\title{
Analysis of the creative motivation and creation mode of Zhang
}

\section{Daqian 's self-portrait}

\section{Li Mao'}

\author{
Neijiang Normal University, Neijiang, Sichuan, 641112
}

\section{Keyword: Zhang Daqian; Self-portrait; Creative motivation ; Creation mode}

\begin{abstract}
Zhang Daqian's self portrait is in the specific historical and cultural background of China, the awakening and examination of self consciousness is the best carrier of the artist's emotional release, personality, ideal and spiritual sustenance. From Zhang Daqian's self portrait in the theme and style of the evolution, we can get a glimpse of a generation of artists creative style and mentality; the creative motivation and creative mode of deeply, we can also appreciate the wise man living in the life circumstances, historical background, cultural tradition and Western art of the trial thought and interpretation.
\end{abstract}

Self-portrait is a special portrait for painters to describe their images, manifest spirit of time and lead off emotions. It has won people's fondness and love ever since ancient times. In foreign countries, artists hid their images ingeniously in the world-famous works, and onymous functions also have joking tastes. Later, self-portrait became an independent art form and appeared in Western art circle. Colorful masterpieces in various forms and great quantities reached the peak in the Renaissance Period, while artists at this time were regarded as excellent and outstanding individuals in the West, which affirmed and developed the art form of self-portrait.

Chinese self-port originated from the Eastern Han Dynasty, and there is the record of Wang Xizhi "trying to paint his self-portrait by looking at the mirror" in The Book of Jin. After Song and Yuan Dynasties, some works were handed down officially, and it prevailed most in the Qing Dynasty. However, because of the hierarchy viewpoints of confucianist and influences of painting of man-of-letters "being elegant and graceful without pursuing similarity in form", these self-portraits were not obvious at that time, and most of them are entrusted in landscape paintings of point view figures like profound scholars, fisherman, etc.

Modern time is an important period for Chinese self-portrait to emerge independently in large scale. Under the influence of Western humanistic thought, self-awareness awakened gradually and Chinese painters who had been seeking for a way out for the nation began to pay attention to themselves and art. They integrated the essence of Chinese figure painting "being lifelike" ingeniously into the creation of self-portrait, either to commemorate, or express their ambitions, trying to make up the absence of humanity in Chinese art history, and Zhang Daqian is outstanding among them. Zhang Daqian always painted his self-portrait in April of Chinese lunar calendar, in which was his birthday, and almost several pieces of works came out every year. All along his life, there were hundreds of such works. Most of the paintings were extemporaneous play. They are of

Introduction to the author: Li Mao (1981-), female, born in Neijiang, Sichuan, master degree, lecturer at

Zhang Daqian School of Fine Arts, Neijiang Normal Univeristy, researcher at Sichuan Zhang Daqian Research

Center and Sichuan Shangri-La Ink and Color Painting Research Institute. 
various forms, designed skillfully and are of profound meanings. They have natural, unrestrained and refined self-mockery humor and unconventional and leisurely temperament.

\section{Creative motivation of Zhang Daqian's self-portrait}

Why Zhang Daqian was so fond of self-portrait creation. Besides his profound painting foundation and his love for figure painting since young, there are also three creative motivations: firstly, it is to complete affirmation of his own role by self-portrait; secondly, it is a record of his own ideals and reminiscence; thirdly, it is a gift to relatives and friends to tell them his recent situation and comfort nostalgia.

Self-portrait is the best way for artists to learn themselves, and it is monologue and witness of their life background, life experience and living state. It is more like a autobiography diary ${ }^{[1] 82}$ to complete understanding and affirmation of one's own social roles, cultural roles and ideal character. Relying on this artistic form, Zhang Daqian presents multiple character such as narcissism, self-entertainment and idealism of his own role, and it also presents Freud's three layers of "id", "ego" and "superego". ${ }^{[2] 28}$

Art needs classic images. As a Sichuan person, Zhang Daqian is not tall, but he has heavy eyebrows, big eyes, pug nose, high forehead and heavy whiskers ${ }^{[3] 211}$, so he is especially "suitable for a painting" because of his peculiar appearances. Zhang Daqian's narcissism is represented in his high affirmation to his image. He once said frankly in his poems on paintings, "Why there are so few handsome men, while there are so many beautiful women under my pen?" It indicates that in his eyes, only Su Dongpo and himself can be called "handsome men", which is also "id" and "creation impulse" represented by Zhang Daqian unconsciously.

Zhang Daqian's era is a turmoil period with numerous and complicated domestic strife and foreign aggression, and it is also a period in which humanistic thought awakened gradually, Chinese and Western culture communicated intensely and crashed intense sparks. In this time background and social realities, he was able to achieve success one way or another and became a celebrity, besides his superb individual charm, artistic accomplishments and survival wisdom, it also has something to do with his life attitude of "magical powers at game" which is reflected in one of his seals. Therefore, the "id" that Zhang Daqian presented in social roles has some self-mockery humor, self-entertainment and amusement spirit. He treated "id" as a means and presented it in the way of "Zhong Kui's self-portrait". He described in the way of "self-dressing" in the preface and postscript, "With a black hat, red robe and ground pattern, everyone laughs that this man is too wildly arrogant. One day, he passes away and goes to Zhongnan Mountain to be the ghost king. The world is full of puppets, and I come on stage in powder. I have got the Changpu Sword to eliminate all the evils in the world." "As long as it is shocking, it works, so what is the use of exorcism. With a broken fan in my hand, I looked up to the sky and laughed."...In these words, he expressed his opinions on survival, reality and himself, but it was also full of humanistic thoughts and care for eliminating all evil spirits and hoping for a peaceful world.

As a spiritual comfort, the creation of self-portrait completes conversations with oneself, while the result of this conversation is to seek an awakening and breaking through and presenting ideal characters. Therefore, the "superego" of Zhang Daqian is in the image of profound scholar with $\mathrm{Su}$ Dongpo as the representative. This is the image that often appears in Zhang Daqian's self-portrait, who wears a Dongpo hat, a long gown and a cloak; he either stands under the pine, or walks among mountains and waters, entrusting his feelings in the ideal characters he yearned for to express the noble, unsullied and refined life aspiration and the carefree and leisurely temperament.

The development of painting is under the influence of different period and different cultural 
background. As a type of painting theme, "self-portrait" has different intension and expression ways in different periods ${ }^{[4] 166}$. Zhang Daqian's self-portrait creation is more about the direct description of his current living situation and the environment and he used changes of his images in different periods to record his ideals and reminiscence, so they have documentary authenticity.

Shanghai in the 1920s and 1930s was the peak of writing and men of letters. The young Zhang Daqian was honored as "an up-rising star" and "expert at Shi Tao" by imitating the great eight and Shi Tao as well as "poem, book, painting and imprint", and he also had the high reputation of "Two heroes in Sichuan" and "South Zhang and north Fu", so this was the time for him to achieve his ambition and enjoy great success. In 1929, when Zhang Daqian was 30 years old, he imitated Shi Tao's Painting of Master under A Pine and painted his Self-portrait of Daqian. In the painting, his face was full of whiskers, and he stood under the age-old pine tree with blazing eyes in high spirit. What was most scarce was that around the painting, it was full of the inscriptions from well-known seniority in literary and art circles, and the number of was as large as 32. For example, there was the inscription from Yang Duti, a gifted man and calligrapher from Hunan, "A handsome young man with beautiful eyes and long beard sit under the pine like an immortal. Whose romantic self-portrait is this? It is Zhang Daqian from Sichuan." There is also the inscription from Xin Hu with profound scholarship in metal and stone painting and calligraphy, "He is a man of books, and from the painting, we can see his predecessor. Who would have thought that a beautiful man with long beard in his thirties would have higher achievement than the ancients." Therefore, we can see that Zhang Daqian had great achievements in his early years, and his artistic talents and reputation has been well-known at that time ${ }^{[5] 207}$.

Self-portrait at 39 Years Old is the most important self-portrait in Zhang Daqian's life, and this is a scarce tinted fine brushwork that rendered the figure almost as a photo. In 1939, the "July 7th Incident" broke up, and Japan invaded China in full scale, and then Beiping was occupied by the enemy. Zhang Daqian, who rebuked Japanese's crimes angrily and "was faithful to his own country despite anything", had the worst plans for himself. In the way of "last painting", he painted himself wearing a Dongpo hat, scepter shoes, Han long gown with long whiskers and cold forehead, sitting under a towering pine tree and in front of limpid flowing water. In the poem HuanXiSha, it is written that "With decades of halter and a worn-out hat, a towering mountain stands here. Who do I leave the paintings for? Gradually, I learned that life was difficult, and it turned out increasingly difficult to return to hometown. Who do I stay in Zhang'an for?" This poem is grand, magnificent, broad and powerful. It presents that though he was in the occupied area, but was not afraid of being bullied by brutal suppression, or being seduced by wealth and position, or prevented by difficulties; it also shown the strong determination that he swore to protect his national integrity as well as his justice conviction. His painting skills of firm strokes and the sharp sense of integrity that faces death unflinchingly and righteous cause stand vividly on the paper. After the success of Anti-Japanese War, Zhang Daqian also painted self-portraits. Currently, a painting in 1946 has been found. It was painted in Chengdu, and was a background-scene-free whole-body sitting statue. In the painting, he leans to the chair in front of the painting table with bright eyes and is full of spirit and energy. His hand that knocks on the painting table lightly cannot reveal his joy for the success of Anti-Japanese War.

In order to seek for better artistic development and avoid the complicated situation in China, though Zhang Daqian had long been famous in foreign countries. However, after tossing about for several times, he had been through all the vicissitudes of life. "It is never too late to come back home." He yearned for his home, but could not come back. Also, with his old age and illness, his right eye almost lost sight, and he could only use his pens and ink full of affection to express 
people's loneliness, dreariness, great pain and deep worries in foreign countries when he was in good state. In 1973, he painted Zhang Daqian's Self-portrait of Begging, which was the real reflection of his complicated and anxious heart. In the painting, though he was strong and muscular and in good bearing, his hair was all white. He had a bamboo in his right hand and a broken bowl in his left hand, looking like begging. He also had a poem, "With a broken bowl in the left hand and a bamboo in the right hand, I walked in the streets starving. I ran through rains and storms with my throat almost husky." Actually, as early as 1950, Zhang Daqian joked about himself in the poem that he was actually "begging for food" by having exhibitions and selling paintings, and he especially asked Zeng Shaojie, a well-known Taiwan engraver, to engrave a seal. Later, "begging for food" almost became a pronoun for him to throw exhibitions. To such a famous painter whose "treasures fill the home", the inside taste affords for thought.

Self-portrait pours out the artists' aspirations, vent their feelings and completes artists' spiritual appeals, and it is the externalization of artists' subject emotions and feelings. When photography was not developed and popularized, self-portrait became the best carrier for Zhang Daqian to tell his relatives and friends about his recent situation and comfort nostalgia.

When Zhang Daqian was still in China. Whenever it was Dragon Boat Festival, Zhang Daqian's favorite activity was to "giving the portrait of Zhong Kui to friends". In 1938, Zhang Daqian escaped Beiping to get out of Japanese's control; he tossed about for several times to get to Chongqing, and he repainted his Self-portrait at 39 Years Old on a fan and wrote a poem Huanxisha; he gave it to his bosom friend Xie Zhiliu as a gift. When they met with each other, they were speechless with tears on both faces. A fan could tell all the words.

After living in foreign countries, whenever Zhang Daqian missed his hometown and relatives, he would paint and send them back. When his relatives saw the paintings, the would feel as if they were seeing him. He used this way to tell that he was safe and express his grief of parting. In 1957, Zhang Daqian sent a self-portrait to his old friend Zhang Muhan in Taiwan from Bade Garden in Brazil. He wrote a poem on the painting, "This is a painting for you. When you see it, it is as if we are talking face to face." He used this poem to express his difficult condition that his ability was not equal to his ambitions. Zhang Daqian's last portrait was sent to his mainland disciple Mi Gengyun when he returned to Taiwan in Moyejing House, when he was 82 years old. This is a half-length side portrait. In the painting, he is healthy in old age, and his beard is as white as snow. It looks as if he is overlooking his hometown across the strait affectionately, and he is looking forward to getting together with his relatives and friends and chatting with them. However, all of this did not come true.

\section{Creation mode of Zhang Daqian's self-portrait}

Zhang Daqian's self-portraits have strong subjective colors and they reflect his unique artistic styles and aesthetic interests. When he was expressing his heart and exploring his inner side, he also formed his unique creation mode gradually.

Most of the modeling of Zhang Daqian's self-portraits comes from the point view figures of Shi Tao's landscape painting and the live-action paintings of his life. He had different representation ways in different periods. When he was young, he liked facing people in the image of "Zhong Kui"; when he became a middle-aged man, he recalled the past with emotion in the image of profound scholars with Su Dongpo as the representative; when he was in old age, his paintings were all full of love for his home and country, and he showed himself in the original appearance.

Zhang Daqian's self-portraits give consideration to both painting and appearance and they 
integrate poems, books and paintings together. He tried different painting techniques boldly and the forms are various without following set forms. However, his favorite was still his left-side image. Most of the figures were meditating quietly, thereby forming distinct contrast with the Zhang Daqian full of comedy sense and ritual sense described by his friend Ye Qianyu.

Zhang Daqian's self-portraits would integrate his new apprehension of Chinese paintings in each period. For example, the most outstanding contribution of Chinese painting, splashing painting method, was applied in the Arbor in Sunlight painted by Zhang Daqian in 1968 and Self-portrait of Zhang Daqian and Black Tiger in 1969. In addition, Zhang Daqian also applied sketching technique and modern photography technique in Western paintings boldly in his creation of self-portraits, which represented his application and reflection on Chinese and Western art and modern science and technology. Though he abandoned shadow depiction which valued realism in the end and returned to the traditional free figure painting, this bold trial had manifested an art master's courage to challenge and innovate as well as the determination and perseverance to pursue authenticity, kindness and beauty. All of them have generated far-reaching influences on the transitions of Chinese art thoughts and the development progress of Chinese art history.

Self-portrait is one of the most important painting themes for Zhang Daqian, a bold trial for Zhang Daqian's loyalty to the essence of traditional Chinese figure painting and courage of exploring the integration of Chinese and Western painting techniques, the best carrier for Zhang Daqian to apply Western sketching and modern photography technique to manifest self-awareness, national spirit and time spirit and important materials to study Zhang Daqian's painting secrets, evolution of painting styles, art progress and mental states in different stages. Zhang Daqian's self-portrait is the awakening and inspection of self-awareness and the painter's leading off of emotions, representation of characters, the yearning for ideals and the spiritual sustenance. The image of Zhong Kui in the paintings is Zhang Daqian's reflection and doubt for the time and social state, and the image of scholar and Han Chinese clothing reflects his lofty mental state, his attachment to traditional culture and manifestation of national sprit and time sprit. From the evolution of his self-portrait themes and styles, we can see a master's art creation progress and mental progress. However, from the theme of self-portrait, Zhang Daqian's endeavors and hard work can both prove this great master's epitome of talents and integrity, which makes us feel more the magnificence and extension of Zhang Daqian art and Chinese painting.

\section{Acknowledgements}

Fund program: Sichuan Province Education Department (Sichuan Zhang Daqian Research Center) Scientific Research Project, Project number ZDQ2011-09

\section{Reference:}

[1]Jiang Hanying. Expression of Freedom: Explanation of Self-portrait Art[J]. Art Exploration, 2010(5).

[2]Qiu Zhenglun. Art Aesthetics[M]. Chongqing: Southwest Normal University Press, 2007.

[3][5]Huang Tiancai. Zhang Daqian for Hundreds of Years[M]. Taiwan: Yizhitang Culture Publishing Co. Ltd., 1998.

[4]Liu Lixue. Manifestation of Self-portrait[J]. Art Theories, 2008(1).

[6]Tang Dichen. Zhang Daqian: Faith Will Never Be Defeated by Violence[J]. Home and Abroad, 2006(8). 